\title{
A point mutation uncouples RNA 3 '-end formation and termination during ribosomal gene transcription in Xenopus laevis
}

\author{
Paul Labhart ${ }^{1}$ and Ronald H. Reeder \\ Fred Hutchinson Cancer Research Center, Division of Basic Sciences, Seattle, Washington 98104 USA
}

Two sites, T2 and T3, in the ribosomal gene spacer of Xenopus laevis both direct RNA 3'-end formation 15 bp upstream of the conserved box sequence GACTTGC. Site T2, which defines the 3 ' end of the $40 \mathrm{~S}$ precursor, does not terminate transcription whereas site $T 3$ at the $3^{\prime}$ end of the spacer does. Here we show that $T 2$ can be converted into a T3-like site with termination activity by a single point mutation 2 bp downstream of the T2 box. RNA 3 '-end formation at T2 is unchanged by this mutation. Conversely, a point mutation 2 bp downstream of the $T 3$ box inhibits termination without affecting $3^{\prime}$-end formation. Our results identify two separable events occurring at the $3^{\prime}$ end of the ribosomal genes: (1) RNA $3^{\prime}$-end formation by processing and (2) transcription termination. The two processes are directed by two distinct, but overlapping, signals in the DNA sequence. Site $\mathrm{T} 2$ in $X$. laevis is damaged in the second process by a natural mutation.

[Key Words: Transcription termination; RNA 3'-end formation; RNA processing; ribosomal genes; RNA polymerase I; Xenopus laevis]

Received May 15, 1989; revised version accepted November 22, 1989.

Initiation of transcription in eukaryotes involves multiple steps; likewise, multiple processes occur at the $3^{\prime}$ ends of genes. Among those processes are release of the transcript, release of the polymerase from the template, and the several steps leading to formation of the mature 3 ' end of the transcript. Complete understanding of the overall process of transcription termination will require separate study of each of the component steps.

For genes transcribed by RNA polymerase II, much has been learned about the steps leading to mature $3^{\prime}$ end formation and some of the factors involved have been identified (for review, see Birnstiel et al. 1985; Platt 1986; see also Galli et al. 1983; Mowry and Steitz 1987; Christofori and Keller 1988). It appears to be true for most, if not all, mRNA genes that the $3^{\prime}$ end of the transcript is formed by endonucleolytic RNA processing (e.g., see Krieg and Melton 1984; Butler and Platt 1988) and that termination occurs at heterogeneous sites farther downstream (Citron et al. 1984; Frayne et al. 1984; Hagenbuechle et al. 1984). Very little is yet known, however, about the process of actual termination and the DNA signals directing it. Formation of the $3^{\prime}$ end of $\mathrm{U} 1$ and $U 2$ small nuclear RNAs (snRNAs) is accomplished by a different mechanism. Here, 3 '-end formation of the precursor is directed by a conserved sequence located

1Present address: Division of Developmental Biology, Medical Biology Institute, La Jolla, California 92037 USA. downstream of the coding region (Hernandez 1985), and the $3^{\prime}$ ends are thought to be generated either by termination or an RNA processing event intimately coupled to transcription. In the case of the tRNA and 5S rRNA genes transcribed by RNA polymerase III, it appears that the 3 ' ends of the transcripts are formed by transcription termination at a cluster of T-residues (Bogenhagen and Brown 1981; Cozzarelli et al. 1983). Likewise, the 3 ' end of the mouse rRNA precursor nearly coincides with the termination signal (Grummt et al. 1985, 1986a; Kuhn and Grummt 1989).

We have recently identified two termination-related elements in the intergenic spacer of the Xenopus laevis ribosomal genes (Labhart and Reeder 1986). Site T2 is located at the $3^{\prime}$ end of the $40 \mathrm{~S}$ precursor coding region and site T3 is situated about $200 \mathrm{bp}$ upstream from the $5^{\prime}$ end of the $40 \mathrm{~S}$ precursor. Both sites share a 7-bp box sequence that is found $15 \mathrm{bp}$ downstream from where the $3^{\prime}$ ends map and the same sequence element is also found at analogous locations in the related species Xenopus borealis. Functional analysis of those sites failed to demonstrate any termination activity of the Xenopus laevis site T2, therefore suggesting that it is an RNA processing site. T3, however, behaved like a terminator, both in nuclear run-on assays and in plasmid injection experiments. Mutational analysis showed that the box is necessary to specify correct $3^{\prime}$ ends at both T2 and $\mathrm{T} 3$ and also for termination at $\mathrm{T} 3$ /Labhart and 
Reeder $1987 \mathrm{a}, \mathrm{b})$. Termination activity was found to reside entirely within a 12 -bp element containing the $\mathrm{T} 3$ box.

The relationship between $\mathrm{T} 2$ and $\mathrm{T} 3$ remained puzzling after those studies. It was unclear how one site could be a processing site, and the other a terminator, yet both were clearly related in DNA sequence. Results in this paper clarify this relationship. We show that RNA 3'-end formation (by processing) and transcription termination at $\mathrm{T} 3$, are two distinct events that can be separated. The two events are directed by two slightly different, but overlapping, signals in the DNA sequence. Because of a naturally occurring single-base mutation, T2 is deficient in termination and retains only the ability to form $3^{\prime}$ ends.

\section{Results}

\section{Experimental design}

All of the plasmids used in this work had the following basic structure (Fig. 1): They contained a ribosomal gene promoter with $245 \mathrm{bp}$ of upstream sequence (thus, including the upstream T3 site in its normal location/ and a 355-bp minigene of rDNA-coding sequences described previously (e.g., see Labhart and Reeder 1987b). This minigene had at its $3^{\prime}$ end the HindIII site that is located at the $3^{\prime}$ end of the 28S rRNA-coding sequence. Between this HindIII site and the EcoRI site at the beginning of the pBR322 sequences, various test fragments containing the $\mathrm{T} 2$ site, the $\mathrm{T} 3$ site, or mutations thereof were cloned (test site; see Fig. 1). Plasmids were injected as circular molecules and in the presence of $500 \mu \mathrm{g} / \mathrm{ml}$ $\alpha$-amanitin into the nuclei of $X$. borealis oocytes. It is important to note that all $\alpha$-amanitin-resistant transcription is strictly promoter dependent. Transcription of the injected plasmids was measured either by analysis of the RNA synthesized in the oocytes, using an S1 protection assay, or by nuclear run-on analysis. By using $\mathrm{S} 1$ probes spanning the test fragments, we analyzed $3^{\prime}$-end formation and readthrough RNA levels at T2, T3, and the mutations thereof; by using $S 1$ probes at sites downstream from the test site, we assayed for termination. As a downstream assay site, we typically used the $\mathrm{T} 3$ region just upstream from the promoter (see Fig. 1) and thus, $\sim 3.7 \mathrm{~kb}$ downstream from the test site. But we found that using other downstream assay sites in the pBR322 sequences gives the same result (data not shown). For the nuclear run-on experiments, transcription rates upstream and downstream of the test fragment were measured by using three single-stranded DNA probes and an RNase-protection assay.

\section{A single-base change restores termination activity to $T 2$}

In the first set of experiments, we injected a series of plasmids that contained $\mathrm{T} 2$, or various mutations of $\mathrm{T} 2$, in the test site. Stable transcripts synthesized in the oocyte were analyzed with two different $\mathrm{S} 1$ probes. One

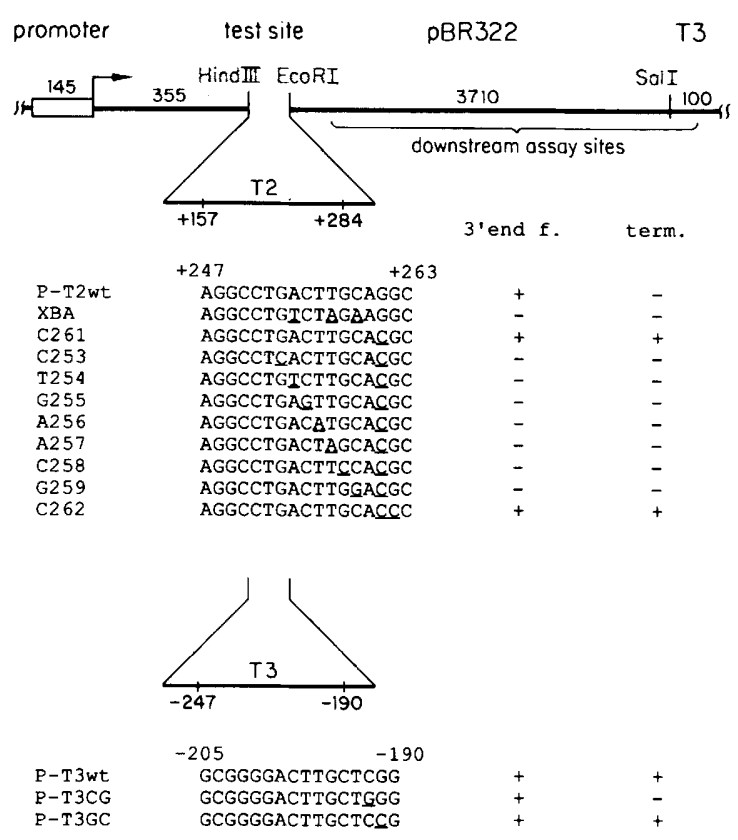

Figure 1. Diagram of plasmid constructions and summary of results. All of the constructs contained a ribosomal gene promoter ( 145 bp/ with a total of $245 \mathrm{bp}$ upstream sequence /thus including the T3 site). Note that for presentation purposes, the plasmid is depicted as linearized just upstream of the promoter and the drawing is not to scale. Various T2- or T3-containing fragments were inserted $355 \mathrm{bp}$ downstream from the initiation site. The termination activity of those fragments is assayed either in the vector sequences or at the T3 upstream from the promoter (downstream assay sites). The sequences surrounding the T2/T3 box (GACTTGC) are shown for all of the constructs, and the mutated bases are underlined. Nucleotide positions at T2 $(+)$ are relative to the HindIII site at the $3^{\prime}$ end of the $28 \mathrm{~S}$ rRNA-coding sequence (see Labhart and Reeder 1987d). Nucleotide positions at $\mathrm{T} 3(-)$ are relative to the transcription start site. The ability of all of the mutants to support 3 '-end formation and termination is indicated at right $(+$ and -$)$.

probe spanned the test site and allowed us to monitor $3^{\prime}$-end formation, as well as readthrough at the T2 element. A second probe measured the amount of RNA synthesized at a far downstream site (the $\mathrm{T} 3$ region, just upstream of the promoter; see diagram in Fig. 2). As a control, we injected a plasmid that had the entire T2 site deleted (Fig. 2, lane 1). As expected, the probe spanning the test site does not detect any RNA (because no RNA homologous to the probe can be synthesized from this template), whereas a strong signal is detected at the downstream assay site. If a wild-type $\mathrm{T} 2$ element is present in the test position, the downstream assay signal remains unchanged compared to the control (lane 3), whereas $3^{\prime}$ ends are detected at T2, along with a low amount of readthrough RNA. This confirms our earlier finding that T2 is a site of RNA $3^{\prime}$-end formation but does not stop transcription (Labhart and Reeder 1986). A cluster of point mutations in the T2 box abolishes 3 '-end formation (lane 2; the additional band is a result of the sequence divergence between the template and the probe at the mutations) but, again, has no effect on the 


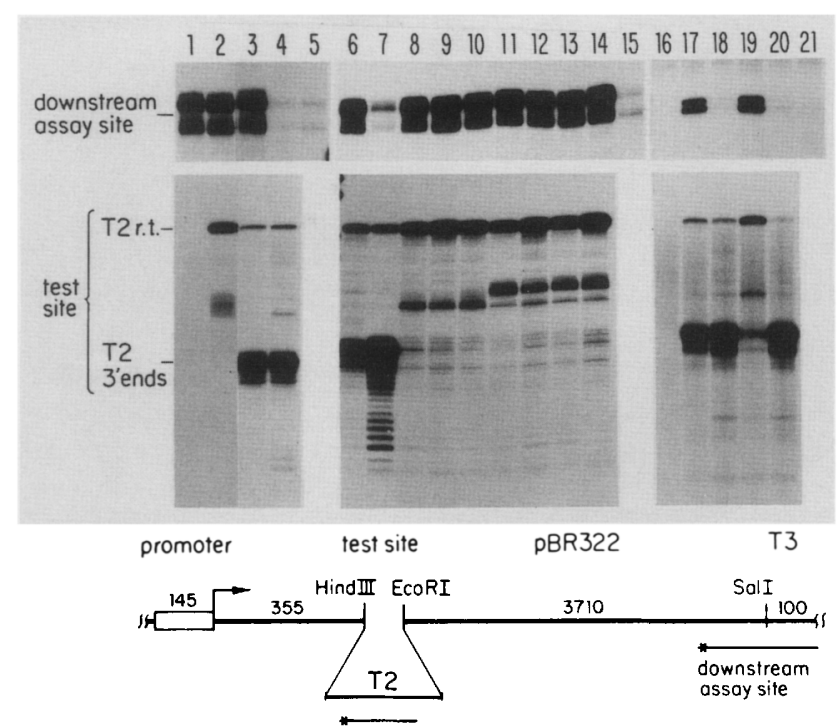

Figure 2. Mutagenesis of $\mathrm{T} 2: 3^{\prime}$-end formation and termination assay. RNA extracted from oocytes that had been injected with the various constructs was analyzed with the $3^{\prime}$-end-labeled T2 probe (middle) and a $3^{\prime}$-end-labeled probe that detects 3 ' ends at the T3 upstream from the promoter /downstream assay site, top). The approximate locations of the probes are shown in the diagram bottom; exact map positions of the probes are given in Methods. The plasmid constructs injected were as follows: (lane 1): control plasmid without insert in test site; (lane 2): XBA; (lanes 3, 6, and 17) P-T2wt; (lanes 4, 7, and 18) C261; (lanes 5, 15, and 21) P-T3wt; (lanes 8 and 19) C253; (lane 9) T254; (lane 10) G255; (lane 11) A256; (lane 12) A257; (lane 13) C258; (lane 14) G259; (lane 16) no plasmid control; (lane 20) C262. Lanes 1-5, 6-15, and 16-21 show the results from three independent experiments. Note that $3^{\prime}$-end formation at $\mathrm{T} 2$ is uncoupled from termination observed at the downstream assay site (cf. lanes 3 with 4,6 with 7,17 and 18).

amount of transcripts detected at the downstream assay site.

We had concluded previously that the nucleotide(s) flanking the conserved 7-bp box sequence must be responsible for the lack of termination activity of T2 (Labhart and Reeder 1987a). On the basis of sequence comparisons of all the fragments tested (in an assay similar to the present one), we predicted that the $\mathrm{G}$ residue $2 \mathrm{bp}$ downstream of the T2 box (position 261; see Fig. 1) may be solely responsible for the lack of termination, because all termination-active fragments had a $\mathrm{C}$ residue in that position. We therefore changed this $\mathrm{G}$ to a $\mathrm{C}$ (plasmid C261), and the result is shown in Figure 2, lane 4 (see also lanes 7 and 18). This $\mathrm{G} \rightarrow \mathrm{C}$ mutation has no effect on 3 '-end formation nor does it change the low amount of readthrough RNA at T2. For reasons that are unclear, the C261 mutation sometimes augments the 3 '-end signal (see lane 7), but this is not obligatory. Invariably, however, the mutation causes a large decrease in the signal seen at the downstream assay site (lanes 4,7 , and 18). Densitometry shows that this decrease is typically $\sim 10$-fold but can be as high as 100-fold. Within a single experiment the decrease in signal at the downstream assay site is as strong as that with $\mathrm{T} 3$ in the test position (cf. lane 4 with 5,7 with 15 , and 18 with 21). Thus, a single-base change converts $\mathrm{T} 2$ into a site with the same termination activity as T3.

We conclude from these experiments that $3^{\prime}$-end formation and termination can be uncoupled by a single base change. Furthermore, this uncoupling has occurred naturally at site $\mathrm{T} 2$ in $X$. laevis.

\section{Single-base changes in the GACTTGC box abolish both $3^{\prime}$-end formation and termination}

To define further the sequences required for the two processes of 3'-end formation and termination, we introduced single-base changes into C261. Thus, all of those mutants have 2 bases changed with respect to the wildtype T2 (the sequences of the double mutants are shown in Fig. 1). We were especially interested to see whether we could find a mutant that would maintain termination but that would abolish 3 '-end formation. As shown in Figure 2 (lanes 8-14) we were not able to find such a mutant. Instead, all base changes in the $7 \mathrm{bp}$ of the box sequence (plasmids C253-G259; Fig. 1) were deleterious to both events. (Note that the additional band in lanes 8-14 results from the sequence divergence between the template and the probe at the mutations.) We also found that the $\mathrm{G}$ residue, $3 \mathrm{bp}$ downstream of the box, which is conserved between all T2 and T3 sites of both $X$. laevis and $X$. borealis, could be changed to a $\mathrm{C}$ (plasmid C262) without affecting either $3^{\prime}$-end formation or termination (Fig. 2, lane 20). It is possible that this is a neutral residue, although other base changes at this location were not tried. Other nucleotides flanking the box sequence were not mutated, but because they are not conserved between the wild-type T3 and C261, they are presumably nonessential for termination.

\section{$3^{\prime}$-end formation and termination can also be uncoupled at $T 3$}

The results obtained with $\mathrm{T} 2$ and the $\mathrm{C} 261$ mutation predict that the two processes of $3^{\prime}$-end formation and termination could also be mutagenically separated at T3. Figure 3 shows the assay of plasmids that have the T3 site, or mutations thereof, in the test position. The RNA produced in injected oocyte injection is analyzed with two S1 probes: one to detect $3^{\prime}$ ends and readthrough at the $\mathrm{T} 3$ element in the test site, and the second one specific for the downstream assay site (see diagram in Fig. 3). With the wild-type $\mathrm{T} 3$ in the test position (plasmid P-T3wt; lanes 1 and 3), correct $3^{\prime}$ ends are formed, and, depending on the experiment, varying amounts of readthrough are detected as well. At the assay site, $\sim 3.7 \mathrm{~kb}$ farther downstream, however, the signal is very low, indicative of the termination activity of T3. The signal is, in fact, as low as with C261 (see direct comparisons in Fig. 2). When the $C$ residue, 2 bp downstream from the box sequence, is changed to a $G$ 


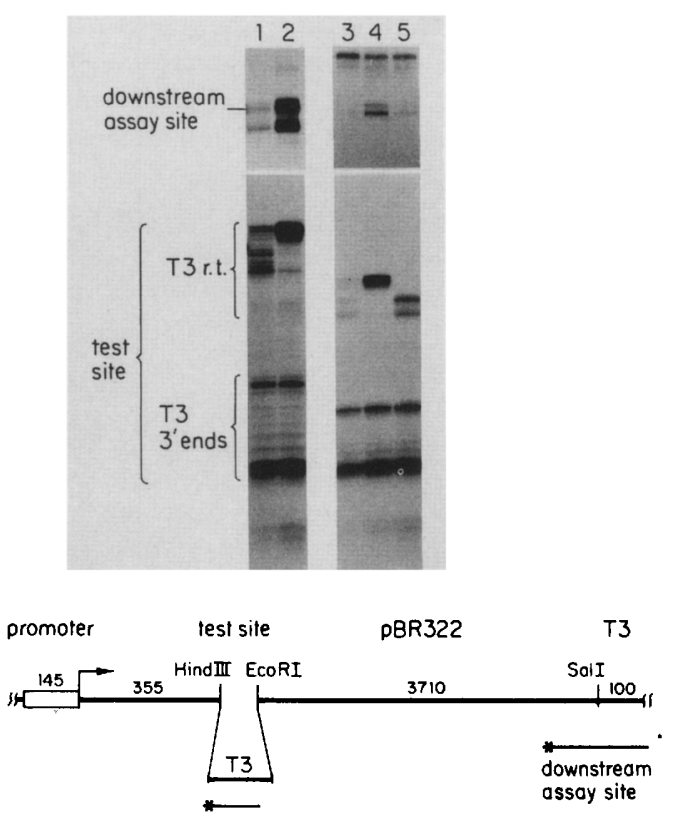

Figure 3. Mutagenesis of T3: 3'-end formation and termination assay. RNA extracted from oocytes that had been injected with the various constructs was analyzed with the $3^{\prime}$-end-labeled T3 probe (middle) and a probe for the downstream assay site (top) as in Fig. 2. The doublet of S1-protected bands is characteristic of $3^{\prime}$ ends at T3. The plasmid constructs injected were as follows: (lanes 1 and 3) P-T3wt; (lanes 2 and 4) P-T3CG; (lane 5) P-T3GC. Lanes 1 and 2, and 3-5, respectively, show the results from two independent experiments. Note that 3 '-end formation at T3 is uncoupled from termination observed at the downstream assay site (cf. lane 1 with 2 , and 3 with 4).

(to make it like the wild-type T2 sequence; plasmid P-T3CG in Fig. 1), termination is affected and the signal at the downstream assay site increases (lanes 2 and 4). By analogy with the results with T2, the levels of $3^{\prime}$ ends at the $\mathrm{T} 3$ in the test site are not changed. This result shows that $3^{\prime}$-end formation and termination can be separated at $\mathrm{T} 3$, as they can at $\mathrm{T} 2$. Also, similar to $\mathrm{T} 2$, the $\mathrm{G}$ residue, 3 bp downstream of the box sequence at $\mathrm{T} 3$, can be changed to a $\mathrm{C}$ without effect (plasmid P-T3GC; lane 5). In a previous paper, we had shown that mutations in the T3 box affect both 3 '-end formation and termination (Labhart and Reeder 1987a). [The probe for T3 in this experiment was prepared from the mutant P-T3CG; therefore, readthrough RNA from the same template yields full-length protection of the probe (lanes 2 and 4), but readthrough RNA from the other plasmids gives rise to shorter protected fragments because of the sequence divergence between the probe and the RNA (lanes 1, 3, and 5).

The combined results show that T3 cannot be functionally distinguished from the $\mathrm{C} 261$ mutation of T2. At both of these sites there are two events that occur: (1) RNA 3 '-end formation by RNA processing and (2) transcription termination. The signals for those two processes in the DNA sequence are overlapping but not identical. The wild-type $\mathrm{T} 2$ differs from $\mathrm{T} 3$ in that the second process is damaged by a single-base change.

\section{The C261 mutation affects the transcription rate}

In the experiments presented so far, we have shown that both the C261 mutation and the wild-type T3 cause a decrease in the amount of steady-state RNA levels detected several kilobases downstream of the site. This decrease in stable RNA could, in principle, be caused either by a decrease in polymerase density (true termination) or by a decrease in transcript stability without release of the polymerase. To distinguish between these possibilities, we performed nuclear run-on experiments. Oocyte nuclei were injected with plasmid templates having various inserts in the test position. After allowing transcription to establish itself, the nuclei were isolated and RNA was labeled by a short pulse in vitro. The labeled RNA was analyzed using three different single-stranded DNA probes in an RNase protection assay. Probe $\mathrm{P}$ measured the initiation rate at the promoter of the various plasmids; in a different study we have demonstrated (P. Labhart and R.H. Reeder, 1989) that reinitiation in this oocyte nuclear transcription system is efficient enough to maintain the in vivo polymerase density at the $5^{\prime}$ end of the gene. Probe A measured the transcription rate $790 \mathrm{bp}$ downstream of the test site; from previous experiments (Hipskind and Reeder 1980; McKnight et al. 1980; P. Labhart, unpubl.|, we can expect RNA polymerase to travel $\sim 750$ bp during a 5-min pulse label in vitro. Therefore, probe A should measure the RNA synthesis capacity of all the polymerases located between the test site and the location of probe $A$ at the moment of nuclear isolation. Probe B measured the transcription rate $3450 \mathrm{bp}$ downstream of the test site. In parallel, total RNA was isolated from the injected oocytes, and steady-state RNA levels at the downstream assay site were determined (probe $C$ in Fig. 4 and Table 1).

An autoradiograph of a typical experiment is shown in Figure 4, and quantitation of results from four independent experiments is shown in Table 1 . The data in Table 1 have been normalized by comparing the signals obtained with probes $\mathrm{P}, \mathrm{A}$, and $\mathrm{B}$ to the signals obtained from a uniformly labeled $\mathrm{T} 7$ polymerase transcript through the same regions (Fig. 4, lane 5). Promoter signals (probe $\mathrm{P}$ ) have been arbitrarily assigned the value of 100 . The steady-state signals (probe $\mathrm{C}$ ) are compared to the signal obtained with the T2wt plasmid, which is given the value of 100 .

The first conclusion to be drawn from the data in Table 1 is that a majority of the polymerase terminates prematurely before it even reaches the test site. In other experiments (data not shown) we have searched for RNA 3 ' ends between the promoter and the test site. When Northern blots were hybridized with a probe to the very $5^{\prime}$ end of the transcripts, we observed abundant short transcripts of $\sim 120$ and 145 nucleotides in length. Those transcripts thus terminate within the "external transcribed spacer" sequence of the minigene. In principle, this attenuation could be attributable to the presence of fortuitous terminator elements or it could indicate that a large proportion of polymerase I has a low processivity and does not elongate very far. We favor the latter possi- 


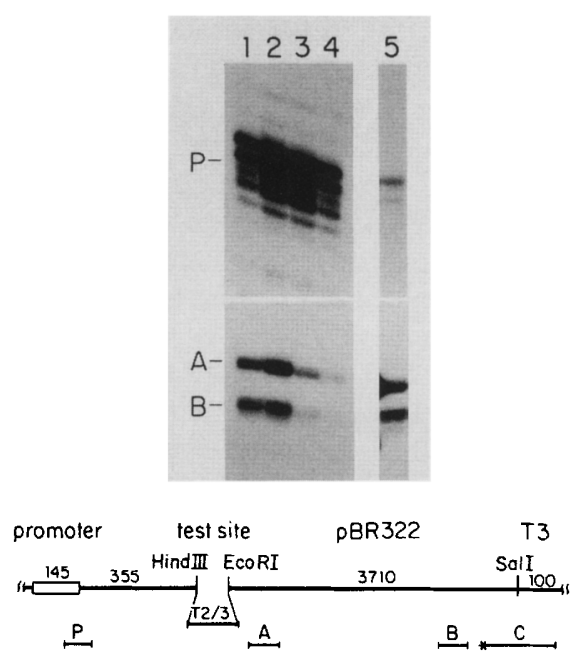

Figure 4. Transcription rates on plasmids injected into oocyte nuclei. Nuclei from oocytes injected with either the control plasmid with no insert in the test site (lane 1), P-T2wt (lane 2), C261 (lane 3) or P-T3wt (lane 4) were pulse labeled for 5 min. The labeled RNA was analyzed with an RNase protection assay, using either probe $\mathrm{P}$ (promoter) or probes $\mathrm{A}$ and $\mathrm{B}$ (downstream assay sites). As a control, RNA-containing sequences complementary to the three probes were synthesized in vitro using T7 RNA polymerase and assayed with the same probes (lane 5). Note that both the wild-type T3 and the C261 mutation of $\mathrm{T} 2$ cause a decrease in the transcription signal obtained with the downstream probes $\mathrm{A}$ and $\mathrm{B}$.

bility because we failed to find any termination activity in the minigene sequence when it was inserted into the test site of the plasmid construct used in the present work (data not shown). We have previously noted similar attenuation of the run-on transcription signal within the endogenous ribosomal gene transcription unit of cultured Xenopus cells (P. Labhart and R.H. Reeder, in prep.; and unpubl.). This attenuation is not T3-dependent, however, and should not affect the interpretation of the fate of polymerase that does reach the test site.

A second conclusion to be drawn from Table 1 (experiment 1) is that insertion of the wild-type T2 site has little or no effect on polymerase density farther downstream, in agreement with the results from analysis of steady-state RNA.

The third and main conclusion is that both the C261 mutation and wild-type T3 cause a 5- to 10-fold decrease in the rate of pulse-labeled RNA synthesis downstream of the test site. The provisional interpretation of these results is that both elements cause a 5 - to 10 -fold decrease in the polymerase density. In each experiment, the decrease in steady-state RNA levels downstream of the C261 mutation was determined in parallel (Table 1, probe $\mathrm{C}$ ) and was found to be similar to the decrease in the pulse label signal. The nuclear run-on data are thus in good agreement with the analysis of stable RNA. We conclude that the $\mathrm{C} 261$ mutation converts $\mathrm{T} 2$ into a site that causes transcription termination.

We note that in some of the experiments shown in
Table 1, the signal detected immediately downstream of T2 (probe A, experiments 2 and 3 ) is three- to fourfold lower than the signal detected farther downstream (probe B). This suggests that there is some instability of the transcript downtream of $\mathrm{T} 2$, even in a 5 -min pulse label. The possible presence of such instability makes it difficult to conclude from these data exactly how soon polymerase leaves the template after encountering T3.

\section{Discussion}

\section{Separation of $3^{\prime}$-end formation from termination}

The novel result of this paper is the demonstration that there are two separable processes that lead to termination of ribosomal gene transcription in $X$. laevis. One process is the formation of RNA $3^{\prime}$ ends $\sim 15$ bp upstream from the box sequence GACTTGC. A second process can be called actual termination and requires the sequence GACTTGCNC. This sequence is present at T3, upstream from the gene promoter, and directs both processes at this site. Only $3^{\prime}$-end formation, but not termination, occurs when the terminal $\mathrm{C}$ is changed to a $\mathrm{G}$ residue, as is the case at site $\mathrm{T} 2$ at the $3^{\prime}$ end of the $40 \mathrm{~S}$ precursor. This base change appears to be a natural mutation characteristic of $X$. laevis because it is found in all three independent rDNA clones sequenced in this region (Labhart and Reeder 1986; and unpubl.). We show that reverting this mutation $(G \rightarrow C)$ restores full termination activity to $\mathrm{T} 2$.

In many cases, it has been difficult to answer the question whether the $3^{\prime}$ ends of transcripts are formed by transcription termination or RNA processing. For site $\mathrm{T} 2$ at the $3^{\prime}$ end of the $X$. laevis $40 \mathrm{~S}$ ribosomal precursor, nuclear run-on data (Labhart and Reeder 1986) and

Table 1.

\begin{tabular}{|c|c|c|c|c|}
\hline \multirow[b]{2}{*}{ Experiment } & \multicolumn{3}{|c|}{ 5-min pulse label } & \multirow{2}{*}{$\begin{array}{l}\text { Steady-state } \\
\text { probe C }\end{array}$} \\
\hline & probe $P$ & probe $\mathrm{A}$ & probe $B$ & \\
\hline T7 control & 100 & 100 & 100 & \\
\hline 1. no insert & 100 & 13 & 12 & 100 \\
\hline T2wt & 100 & 12 & 8 & 100 \\
\hline C261 & 100 & 2 & 1 & 18 \\
\hline T3wt & 100 & 1 & 0.3 & 14 \\
\hline 2. T2wt & 100 & 6 & 20 & 100 \\
\hline $\mathrm{C} 261$ & 100 & 3 & 3 & 13 \\
\hline 3. $\mathrm{T} 2 \mathrm{wt}$ & 100 & 3 & 13 & 100 \\
\hline C261 & 100 & 1 & 1 & 12 \\
\hline 4. $\mathrm{T} 2 \mathrm{wt}$ & 100 & 8 & 6 & 100 \\
\hline C261 & 100 & 2 & 1 & 20 \\
\hline
\end{tabular}

Quantitation of the transcription signals obtained with the nuclear run-on experiment shown in Fig. 4 plus the results from three further independent experiments. Experiment 4 was done with $X$. laevis oocytes. For each experiment, total RNA was analyzed in parallel, using probe $\mathrm{C}$ and the $\mathrm{S} 1$ protection assay. The nuclear run-on signals are normalized to the T7 RNA control and compared to the signal at the promoter $(=100)$. The S1 assay signals are compared to the signal obtained with P-T2wt $(=100)$. 
plasmid injection experiments similar to the ones in this paper (Labhart and Reeder 1987a) had previously indicated that the $3^{\prime}$ ends of the precursor are formed in the absence of detectable termination and must therefore be formed by RNA processing. By showing that termination can be uncoupled from 3 '-end formation we provide further proof that the $3^{\prime}$ ends at $\mathrm{T} 2$ are not formed by transcription termination and, therefore, have to be the result of some RNA processing event. Likewise, at T3, even though this site is active in termination, the RNA 3 ' ends are probably also formed by RNA processing, because the termination efficiency of the site can be affected by a point mutation (P-T3CG; Fig. 3) without changing the level of $3^{\prime}$ ends. If the ends at $\mathrm{T} 3$ were formed by the transcription termination event measured at the downstream assay site, a mutation that affects termination should also lead to a decrease in the level of RNA 3' ends. This result is not observed.

The processing event identified here as a first step leading to transcription termination by RNA polymerase I appears not to be a conventional type of RNA processing. We had found previously that 3 '-end formation at T2 is only observed if transcripts are made by RNA polymerase I. Furthermore, we have failed to find correct cleavage of in vitro-synthesized precursors upon reinjection into oocyte nuclei. Finally, readthrough transcripts made by RNA polymerase I under heat shock conditions are very stable upon temperature downshift (Labhart and Reeder 1987c; and unpubl.). All of those data suggest that the processing event at $\mathrm{T} 2$ and $\mathrm{T} 3$ is most likely closely linked to transcription.

Although our results clearly uncouple $3^{\prime}$-end formation from termination, the two processes are not necessarily completely independent. It is still possible that for termination to take place, the first step, 3 '-end formation by RNA processing, has to occur.

\section{Where does polymerase release from the template?}

As discussed above, the finding that 3 '-end formation and termination can be uncoupled strongly suggests that the 3' ends are formed by RNA processing and, therefore, termination has to occur farther downstream. On the other hand, measurements of transcription rates immediately downstream of the test site (probe A; Fig. 4 and Table 1) indicate that termination induced by C261 and T3 may be quite rapid. We are cautious in this conclusion, however, because the data of Table 1 indicate that the signal detected by probe A may be an underestimate as a result of RNA instability.

We have attempted to locate the actual sites of polymerase release by preparing a $3^{\prime}$-end-labeled probe for T2 and C261 that extends $600 \mathrm{bp}$ into the vector sequences. We could not find any discrete sites of 3 '-end formation downstream of $\mathrm{C} 261$ that were absent downstream of the wild-type T2 (data not shown). The combined results therefore favor a model in which an event occurs at the terminator that potentiates polymerase release, but actual termination of transcription occurs at heterogeneous sites downstream.
We also note that even though the decrease in both steady-state RNA levels and transcription rates downstream of T3 or C261 is significant and reproducible (but varies in magnitude from experiment to experiment), transcription is still clearly detectable. This is in contrast to the results obtained with $\mathrm{T} 3$ in its normal location upstream from the promoter: Transcription within the promoter and readthrough of the initiation site is extremely low, both on endogenous genes and on injected plasmids (Labhart and Reeder 1986, 1987a). These findings suggest that the rapidity of polymerase release depends on what sequence the polymerase encounters downstream of the terminator element and that the presence of an active promoter may contribute to efficient and rapid termination. We are currently testing this notion.

\section{Comparison to termination in other systems}

The other polymerase I termination system that has been studied extensively is that of the mouse. There are many similarities between the mouse and Xenopus systems. In both systems, two regions with terminatorlike activity have been identified, one defining the $3^{\prime}$ end of the large rRNA precursor, and the other located immediately upstream of the gene promoter (Grummt et al. 1985, 1986b; Henderson and Sollner-Webb 1986). Likewise, in both systems, termination is directed by short conserved DNA sequences (Grummt et al. 1986a). Unlike the situation in $X$. laevis, both terminator regions in the mouse appear to contain real termination sites. We can now say, however, that this is not a fundamental difference because T2 in $X$. laevis also appears to be a terminator, albeit one that is inactivated by a natural point mutation.

It has been reported recently that $3^{\prime}$-end formation of mouse rRNA involves transcription termination, followed by a trimming of the terminated RNA by $\sim 10 \mathrm{nu}$ cleotides (Kuhn and Grummt 1989). It is important to note that those two steps clearly do not correspond to the two processes identified in this paper, but-if an analogy is possible-both steps are part of our first process, 3 '-end formation. Assays for termination that monitor RNA levels or transcription rates downstream from the site of 3 '-end formation, as used in this present work, were not employed in that study.

If RNA polymerase I actually does terminate according to the two-step model proposed above, then the events at the $3^{\prime}$ end of the ribosomal genes of $X$. laevis begin to look similar to the events at the $3^{\prime}$ ends of genes transcribed by RNA polymerase II: the first step being processing (often followed by polyadenylation), and the second step being termination at heterogeneous sites farther downstream. For both polymerase I and II, the first step can be performed independent of termination. In contrast to polymerase I transcripts, however, polymerase II transcripts can clearly be processed long after transcription has occurred (e.g., see Krieg and Melton 1984; Price and Parker 1984: Lewis and Manley 1986; Butler and Platt 1988; Christofori and Keller 1988). 
However, similar to our results in mutating bases in the 7-bp box sequence, it has been found that mutations in the conserved AATAAA polyadenylation signal affect both 3'-end formation and termination (Whitelaw and Proudfoot 1986; Logan et al. 1987; Connelly and Manley 1988). The polyadenylation or 3 ' processing signal, however, is not sufficient for termination, and additional signals, still ill-defined but mostly located farther downstream, are required (Birchmeier et al. 1984; Falck-Pedersen et al. 1985; Sato et al. 1986). Despite some differences, it is thus possible that termination by both RNA polymerases may occur by a fundamentally similar process.

\section{Methods}

Plasmid constructions and mutagenesis

For mutagenesis of the $X$. laevis T2 site, an Aval fragment from +157 to +284 relative to the unique HindIII site (numbering according to Labhart and Reeder 1987d) was blunt-ended and cloned into the SalI site of M13mpl8 using Sall linkers. For mutagenesis of the $X$. laevis T3 site, a fragment from -247 to -190 , relative to the transcription start site, was cloned between the BamHI and the SalI sites of M13mp19. Site-directed mutagenesis was performed on the basis of a method described by Kunkel (1985). The protocol followed and the materials used for the mutagenesis were from Bio-Rad (Muta-Gene in vitro mutagenesis kit). Mutant oligonucleotides were 17 or $19 \mathrm{nu}$ cleotides long with the mutant base in the center. Replicative forms of the mutagenized M13mp18/19 clones were grown, and the T2 or T3 insert including the flanking polylinker sequences was released using HindIII and EcoRI. Those fragments were then cloned between the HindIII and EcoRI sites of our minigene described previously (e.g., see Labhart and Reeder 1987b).

As the T7 RNA control for the nuclear nun-on experiment (Fig. 4, lane 5), a linker-scanner mutant (LS-7/+3; Reeder et al. 1987) was cloned downstream of the $T 7$ promoter in the vector pGEM-3 (Promega). Using this template and T7 RNA polymerase, an RNA could be synthesized that, in the RNase protection assay with probe $\mathrm{P}$, yielded a similar protected RNA fragment as correctly initiated ribosomal transcripts. In addition, equimolar amounts of the sequences complementary to probes A and B were present in this T7 RNA.

\section{Oocyte injections and RNA analysis}

Oocyte injections, extraction of total RNA, and S1 analysis were performed as described previously (Labhart and Reeder $1987 \mathrm{~b})$. Nuclear run-on reactions using manually isolated germinal vesicles and the RNase protection assay were performed as described (Labhart and Reeder 1986, 1987a). With the exception of experiment 4 in Table 1 , all experiments shown were performed using oocytes of $X$. borealis.

For quantitation of the protected DNA or RNA fragments, appropriate exposures of autoradiographs were scanned with a Videk $1 \mathrm{~K} \times 1 \mathrm{~K} \mathrm{CCD}$ camera coupled with image analysis on a Sun $3 / 260$ computer (Sun Microsystems) with Visage 2000 software (BioImage).

\section{Single-stranded DNA probes}

For the S1 protection assay, restriction fragments were 3 '-endlabeled with DNA polymerase (large fragment) and the appropriate deoxynucleoside triphosphate or $5^{\prime}$-end-labeled using po- lynucleotide kinase. The labeled fragments were denatured in $0.3 \mathrm{M} \mathrm{NaOH}$, and the two strands were separated on preparative, native polyacrylamide gels. No S1-resistant probe is observed in the absence of complementary RNA (see Fig. 2, lanes 1 and 16); therefore, under our S1 assay conditions, full-length protected probe is a quantitative measure for readthrough transcripts.

The 3'-end-labeled probe to monitor RNA 3'-end formation at T2 has been described previously (Labhart and Reeder 1986). The $3^{\prime}$-end-labeled probe to monitor RNA 3'-end formation at T3 (Fig. 3) was labeled at the HindIII site of P-T3CG and extended to the BamHI site at the $3^{\prime}$ end of the T3 insert; it had a length of 83 nucleotides. The probe for T3 upstream from the promoter (downstream assay site in Figs. 2 and 3 and probe $C$ in Fig. 4) was 3 '-end-labeled at the HinfI site at nucleotide 852 on the pBR322 map and extended to the HinfI site at -125 in the gene promoter; it had a total length of 324 nucleotides.

For the experiment of Figure 4 and Table 1, an AluI fragment of 63 nucleotides (pBR322 map position $3656-3719$, probe $A$ ) and a HaeIII fragment of 57 nucleotides (pBR322 map position 991-1048, probe B) were cloned into $M 13 \mathrm{mp} 18 / 19$ and used as single-stranded probes was in the RNase protection assay. Probe $P$ extends from -34 to +34 , relative to the initiation site, and has been described previously (Labhart and Reeder 1987a).

\section{Acknowledgments}

This work was supported by a grant from the National Institutes of Health to R.H.R and a Special Fellowship of the Leukemia Society of America to P.L. We thank Paul Goodwin for help with scanning autoradiographs.

\section{References}

Birchmeier, C., D. Schuemperli, G. Sconzo, and M.L. Birnstiel. 1984. 3' editing of mRNAs: Sequence requirements and involvement of a 60-nucleotide RNA in maturation of histone mRNA precursors. Proc. Natl. Acad. Sci. 81: 1057-1061.

Birnstiel, M.L., M. Busslinger, and K. Strub. 1985. Transcription termination and 3 ' processing: The end is in site! Cell 41: 349-359.

Bogenhagen, D.F. and D.D. Brown. 1981. Nucleotide sequences in Xenopus 5S DNA required for transcription termination. Cell 24: 261-270.

Butler, J.S. and T. Platt. 1988. RNA processing generates the mature $3^{\prime}$ end of yeast $\mathrm{CYCl}$ messenger RNA in vitro. Science 242: 1270-1274.

Christofori, G. and W. Keller. 1988. 3' Cleavage and polyadenylation of mRNA precursors in vitro requires a poly(A) polymerase, a cleavage factor, and a snRNP. Cell 54: 875-889.

Citron, B., E. Falck-Pedersen, M. Salditt-Georgieff, and J.E. Darnell. 1984. Transcription termination occurs within a 1000 base pair region downstream from the poly $(A)$ site of the mouse $\beta$-globin (major) gene. Nucleic Acids Res. 12: 87238731.

Connelly, S. and J.L. Manley. 1988. A functional mRNA polyadenlylation signal is required for transcription termination by RNA polymerase II. Genes Dev. 2: 440-452.

Cozzarelli, N.R., S.P. Gerrard, M. Schlissel, D.D. Brown, and D.F. Bogenhagen. 1983. Purified RNA polymerase III accurately and efficiently terminates transcription of 5S RNA genes. Cell 34: 829-835.

Falck-Pedersen, E., J. Logan, T. Shenk, and J.E. Darnell. 1985. Transcription termination within the ElA gene of adeno- 
virus induced by insertion of the mouse $\beta$-major globin terminator element. Cell40: 897-905.

Frayne, E.G., E.J. Leys, G.F. Crouse, A.G. Hook, and R.E. Kellems. 1984. Transcription of the mouse dihydrofolate reductase gene proceeds unabated through seven polyadenylation sites and terminates near a region of repeated DNA. Mol. Cell. Biol. 4: 2921-2924.

Galli, G., H. Hofstetter, H.G. Stunnenberg, and M.L. Birnstiel. 1983. Biochemical complementation with RNA in Xenopus oocytes: A small RNA is required for the generation of 3 ' histone mRNA termini. Cell 34: 823-828.

Grummt, I., U. Maier, A. Oehrlein, N. Hassouna, and J.-P. Bachellerie. 1985. Transcription of mouse rDNA terminates downstream of the $3^{\prime}$ end of 28S RNA and involves the interaction of factors with repeated sequences in the $3^{\prime}$ spacer. Cell 43: 801-810.

Grummt, I., H. Rosenbauer, I. Niedermeyer, U. Maier, and A. Oehrlein. 1986a. A repeated $18 \mathrm{bp}$ sequence motif in the mouse rDNA spacer mediates binding of a nuclear factor and transcription termination. Cell 45: 837-846.

Grummt, I., A. Kuhn, I. Bartsch, and H. Rosenbauer. 1986b. A transcription terminator located upstream of the mouse rDNA initiation site affects rRNA synthesis. Cell 47: $901-$ 911.

Hagenbuechle, O., P.K. Wellauer, D.L. Cribbs, and U. Schibler. 1984. Termination of transcription in the mouse $\alpha$-amylase gene Amy-2a occurs at multiple sites downstream of the polyadenylation site. Cell 38: 737-744.

Henderson, S. and B. Sollner-Webb. 1986. A transcriptional terminator is a novel element of the promoter of the mouse ribosomal RNA gene. Cell 47: 891-900.

Hernandez, N. 1985. Formation of the $3^{\prime}$ end of Ul snRNA is directed by a conserved sequence located downstream of the coding region. EMBO J. 4: 1827-1837.

Hipskind, R.A. and R.H. Reeder. 1980. Initiation of ribosomal RNA chains in homogenates of oocyte nuclei. J. Biol. Chem. 255: 7896-7906.

Krieg, P.A. and D.A. Melton. 1984. Formation of the $3^{\prime}$ end of histone mRNA by post-transcriptional processing. Nature 308: 203-206.

Kuhn, A. and I. Grummt. 1989. 3'-end formation of mouse prerRNA involves both transcription termination and a specific processing reaction. Genes Dev. 3: 224-231.

Kunkel, T.A. 1985. Rapid and efficient site-specific mutagenesis without phenotypic selection. Proc. Natl. Acad. Sci. 82: $488-492$.

Labhart, P. and R.H. Reeder. 1986. Characterization of three sites of RNA $3^{\prime}$-end formation in the Xenopus ribosomal gene spacer. Cell 45: 431-443.

. 1987a. A 12-base-pair sequence is an essential element of the ribosomal gene terminator in Xenopus laevis. Mol. Cell. Biol. 7: 1900-1905.

1987b. Ribosomal precursor 3 '-end formation requires a conserved element upstream of the promoter. Cell 50: $51-$ 57.

. 1987c. Heat shock stabilizes highly unstable transcripts of the Xenopus ribosomal gene spacer. Proc. Natl. Acad. Sci. 84: $56-60$.

. 1987d. DNA sequences for typical ribosomal gene spacers from Xenopus laevis and Xenopus borealis. Nucleic Acids Res. 15: 3623-3624.

- 1989. High initiation rates at the ribosomal gene promoter do not depend upon spacer transcription. Proc. Natl. Acad. Sci. 86: 3155-3158.

Lewis, E.D. and J.L. Manley. 1986. Polyadenylation of an mRNA precursor occurs independently of transcription by
RNA polymerase II in vivo. Proc. Natl. Acad. Sci. 83: 85558559.

Logan, J., E. Falck-Pederson, J.E. Darnell, and T. Shenk. 1987. A poly(A) addition site and a downstream termination region are required for efficient cessation of transcription by RNA polymerase II in the mouse $\beta^{\text {maj }}$ globin gene. Proc. Natl. Acad. Sci. 84: 8306-8310.

McKnight, S.L., R.A. Hipskind, and R.H. Reeder. 1980. Ultrastructural analysis of ribosomal gene transcription in vitro. J. Biol. Chem. 255: 7907-7911.

Mowry, K.L. and J.A. Steitz. 1987. Identification of the human U7 snRNP as one of several factors involved in the 3 '-end maturation of histone premessenger RNA's. Science 238: $1682-1687$.

Platt, T. 1986. Transcription termination and the regulation of gene expression. Annu. Rev. Biochem. 55: 339-372.

Price, D.H. and C.S. Parker. 1984. The 3' end of Drosophila histone $\mathrm{H} 3$ mRNA is produced by a processing activity in vitro. Cell 38: 423-429.

Reeder, R.H., D. Pennock, B. McStay, I. Roan, E. Tolentino, and P. Walker. 1987. Linker scanner mutagenesis of the Xenopus laevis ribosomal gene promoter. Nucleic Acids Res. 15: 7429-7441.

Sato, K., R. Ito, K.-H. Baek, and K. Agarwal. 1986. A specific DNA sequence controls termination of transcription in the gastrin gene. Mol. Cell. Biol. 6: 1032-1043.

Whitelaw, E. and N. Proudfoot. 1986. $\alpha$-Thalassaemia caused by a poly(A) site mutation reveals that transcriptional termination is linked to 3 '-end processing in the human $\alpha 2$ globin gene. EMBO I. 5: 2915-2922. 


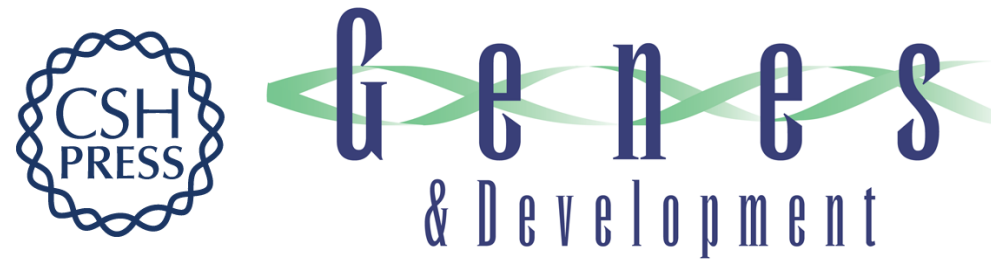

\section{A point mutation uncouples RNA 3'-end formation and termination during ribosomal gene transcription in Xenopus laevis.}

P Labhart and R H Reeder

Genes Dev. 1990, 4:

Access the most recent version at doi:10.1101/gad.4.2.269

References This article cites 36 articles, 15 of which can be accessed free at:

http://genesdev.cshlp.org/content/4/2/269.full.html\#ref-list-1

License

Email Alerting

Service

Receive free email alerts when new articles cite this article - sign up in the box at the top right corner of the article or click here.

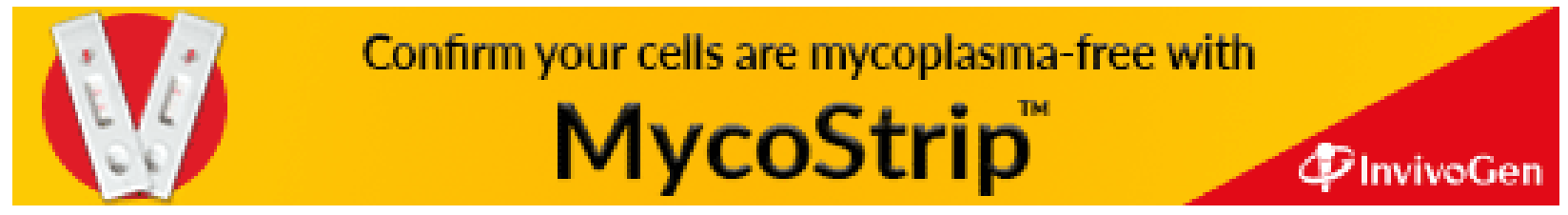

